\title{
Assessment of Polycyclic Aromatic Hydrocarbons (Pahs) in Hardwood, Palmwood and Softwood - Smoked Fish
}

\author{
Ezike Christopher Onyemaechi", Ohen Jessica Ndudi, Echor Felix Okaliwe \\ Department of Animal/Fisheries Science \& Management, Enugu State University of Science \& Technology (ESUT), Enugu, Nigeria
}

Email address:

Christopher.ezike@esut.edu.ng (E. C. Onyemaechi)

${ }^{*}$ Corresponding author

\section{To cite this article:}

Ezike Christopher Onyemaechi, Ohen Jessica Ndudi, Echor Felix Okaliwe. Assessment of Polycyclic Aromatic Hydrocarbons (Pahs) in Hardwood, Palmwood and Softwood - Smoked Fish. International Journal of Ecotoxicology and Ecobiology.

Vol. 2, No. 4, 2017, pp. 178-181. doi: 10.11648/j.ijee.20170204.17

Received: December 11, 2017; Accepted: December 28, 2017; Published: January 11, 2018

\begin{abstract}
Three types of woods were investigated; hard wood HWS Mahogany (Mellicae), soft wood SWS Bamboo (Mycapella) and oil palm wood PWS Elaeis guineensis to smoke African catfish Clarias gariepinus. The Polycyclic Aromatic Hydrocarbons (PAHs) in the experimental fish were extracted using solvents and Ultrasonication and were analyzed for 15 Polycyclic Aromatic Hydrocarbons using high performance liquid chromatography (HPLC) with ultraviolet diode detector. There was no significant difference between the three woods investigated $(\mathrm{P}>0.05)$ in benzo_b fluoranthene and benzo_a pyrene but significant differences $(\mathrm{P}<0.05)$ in PAH occurred between the 3 wood-smoked fish in acenaphthene, fluorine, phenathrene, anthracene, pyrene, dibenzo_ah anthracene, benzo_ghi pyrene, indeno $123 \mathrm{c}$ pyrene, fluoranthene with lowest value in PWS. Naphthalene and acenaphthylene had same value in HWS and SWS but were significantly lower in PWS. Conversely, benz_a athracene showed higher value in HWS compared to SWS and PWS but chrysene displayed higher value in SWS compared to PWS and HWS. It can be concluded that the use of Elaeis guineensis is preferred in smoking of $C$. gariepinus compared to Bamboo and Mahogany. Since the three woods did not differ in benzo a pyrene, high value of benz_a anthracene recorded in HWS fell below carcinogenic ranges, hence usage may not impact on human health.
\end{abstract}

Keywords: Polycyclic Aromatic Hydrocarbons, Smoked Fish, Clarias gariepinus

\section{Introduction}

Polycyclic aromatic hydrocarbons (PAHs) are a class of lipophillic compounds comprised of chemical compounds known to be potent carcinogens. PAHs are present in water, air, soil and traces in various food products. Food can become contaminated during thermal treatments that occur in processes of food preparation and manufacturing such as drying, smoking, cooking, roasting, baking and frying [16]. Most PAHs are Ubiquitous environmental pollutants resulting from the incomplete combustion or pyrolysis of organic matter during industrial processing and various human activities [5]. They originate from diverse sources such as tobacco smoke, engine exhausts, petroleum distillates, and coal-derived products, with combustion sources predominating [19]. Due to their carcinogenic activity, PAHs have been included in the European Union and the United States Environmental Protection Agency (USEPA) priority pollutant lists. Human exposure to PAHs accounts for 58 to $98 \%$ of such contamination [11]. Processing of food at high temperatures from grilling, smoking, roasting and frying are major sources of generating PAHs. Levels as high as $200 \mu \mathrm{g} / \mathrm{kg}$ have been found for individual PAH in smoked fish and meat samples for instance in barbecued meat, $130 \mu \mathrm{g} / \mathrm{kg}$ has been reported whereas the average background values are used in the ranges of 0.01 to $1 \mu \mathrm{g} / \mathrm{kg}$ in uncooked foods [14].

Fish is a rich source of lysine suitable for supplementing high carbohydrate diet. It is a good source of thiamin, riboflavin vitamins $\mathrm{A}$ and $\mathrm{D}$, phosphorus, calcium and iron. It is high in poly unsaturated fatty acids that are important in lowering blood cholesterol level [2]. One of the greatest problems affecting the fishing industry all over the world is fish spoilage. In high ambient temperature of the tropics, fresh fish spoil within 20 hours [9]. Attempt has been made 
to reduce fish spoilage through improved preservation techniques.

Fish smoking belongs to one of the oldest technologies of food preservation which mankind has used in fish processing. Smoking has become a means of offering diversified high value added products as an additional marketing option for certain fish species where fresh consumption becomes limited [13]. Traditional smoking techniques involve treating of whole or filleted fish with smoke from wood and burning that comes into direct contact with the product. This can lead to its contamination with PAHs if the process is not adequately controlled or if very intense smoking procedures are employed [4]. The smoke is produced by shouldering wood inside an open drum, directly below the hanging fish or hang-out mesh trays.

The level of PAHs in smoked food depends on the smoking process including type of smoke generator, combustion temperature and degree of smoking [1]. The combustion of the smoke and the condition of processing affect the sensory quality, shelf life and wholesomeness of the product. Potential health hazards associated with smoked foods may be caused by carcinogenic components of wood smoke: mainly PAHs, derivatives of PAHs such as nitro-PAH or oxygenated PAH and to a less extent heterocyclic amines [20]. The smoke for smoking of food develops due to the partial burning of wood, predominantly hard wood, softwood and biogases. Among PAHs, the benzo _a pyrene (bap) concentration has received particular attention due to its higher contribution to over all burden of cancer in humans, being used as a marker for the occurrence and effect of carcinogenic PAHs in food [18].

PAHs in food samples have been analyzed by high performance lipid chromatography (HPLC) with ultraviolet (UV) or fluorescence detection (FCD), gas chromatography mass spectrometry, (GC- MS). Most of these methods however require sample preparation steps, such as extraction, concentration and isolation, to enhance the sensitivity and selectivity of their detection. For example, liquid-liquid extraction with several organic solvents, pressurized liquid extraction, gel permeation or open column chromatography and solid- phase extraction (SPE) have been used as clear-up procedures [3]. These contemporary analytical procedures make it possible to determine individual PAH in smoked foods at concentrations of the order of $0.1 \mu \mathrm{g} / \mathrm{kg}$ or even $0.01 \mu \mathrm{g} / \mathrm{kg}$ [21]. The present study was therefore conducted to investigate the levels of polycyclic aromatic hydrocarbon (PAHs) in hard wood, palm wood and soft wood- smoked fish.

\section{Materials and Methods}

\subsection{Experimental Site}

African Catfish (Clarias gariepinus) was smoked in the Research Laboratory of the Department of Animal/Fisheries Science and Management, Faculty of Agriculture and Natural Resources, Enugu State University of Science and
Technology (ESUT) Enugu Nigeria (latitude $074^{\circ}$ North and $082^{\circ}$ South and longitude $068^{\circ}$ East and $076^{\circ}$ West with annual mean temperature at $30^{\circ} \mathrm{C}$ ), and was sent to Nigeria Institute for Oceanography and Marine Research (NIOMR) Lagos Nigeria, for PAHs study.

\subsection{Collection and Transportation of Experimental Fish}

African catfish, Clarias gariepinus) was obtained from a fish farm in Enugu metropolis. The fish was transported to the Departmental Smoking Laboratory where the smoking was carried out. Ethical clearance from the Enugu State University of Science and Technology Committee on Experimental Animal Care was obtained and followed.

\subsection{Fish Preparation and Smoking}

Three types of woods were investigated; hard wood HWS Mahogany (Mellicae), soft wood SWS Bamboo (Mycapella) and oil palm wood PWS Elaeis guineensis to smoke African catfish Clarias gariapenus. The Polycyclic Aromatic Hydrocarbons (PAHs) in the experimental fish were extracted using solvents and Ultrasonication and were analyzed for 15 Polycyclic Aromatic Hydrocarbons using high performance liquid chromatography (HPLC) with ultraviolet diode detector

\subsection{Chemical Analysis}

Each type of smoked dried fish was weighed into a number of glass bottles and extracted sequentially by ultrasonication using $25 \mathrm{ml}$ of $\mathrm{n}$-hexane for $1 \mathrm{hr}$. The supernatant of the extracts were decanted into a vial and $15 \mathrm{ml}$ of fresh solvent was added for another 1 hour of ultrasonication. The process was repeated with another $10 \mathrm{ml}$ of fresh solvent for 1 hour and the combined extracts $(50 \mathrm{ml})$ were centrifuged at 2500 rpm for 10mins and the supernatant was decanted [12] and cleaned -up using the whatman nylon filter membrane. Further clean-up was done using the solid phase extraction (SPE) cartridges.

The sorbent of the SPE cartridges were first conditioned with n-hexane after which the filtered extracts were loaded on to the cartridges, the analytes were eluted with dichloromethane. The volume of the dichloromethane was blown down to dryness and extract was reconstituted in $200 \mu 1$ of acetonitrile. Thereafter high performance liquid chromatography (HPLC) was used for separation and analysis. The quantification of PAHs was performed using an Agilent 1100 model HPLC system. Separation of the PAHs was performed on a monomeric type vetadecyl silica column, supereosil Lc PAH $2 \mathrm{~cm} \times 4.6 \mathrm{~mm}$ containing $5 \mu \mathrm{m}$ particles at ambient temperature $\left(25 \pm 1^{\circ} \mathrm{C}\right)$ and a flow rate of $1.0 \mathrm{ml} / \mathrm{min}$. Gradient elution using acetonitrile and water was employed (60:40 to 0.100$)$ with peak detection and integration of data using Chemstation Software Series. External calibration was carried out using mixed PAHs standards from the chromatogram. All solvents used were of high purity analytical grade obtained from Super co, Bellefonte, PA, USA. 


\subsection{Statistical Analysis}

Data collected were subjected to 1 way analysis of variance (ANOVA) using SPSS version 20. Comparisons among means were carried out using Duncan Multiple Range Tests (DMRT) at significance level of $(\mathrm{P}<0.05)$.

\section{Results}

The results on Length, weight and fat content of fish used in the study are represented in Table 1

Table 1. Length, Weight and Fat Content of Fish.

\begin{tabular}{llll}
\hline Length $(\mathbf{c m})$ & Wet weight $(\mathrm{g})$ & Dry weight $(\mathbf{g})$ & Fat $\left(\mathbf{m g g}^{-1}\right)$ \\
\hline $36.8-38.5$ & $450-525$ & $107.65-139.23$ & $49.735 \pm 0.45$ \\
\hline
\end{tabular}

The average length $(\mathrm{cm})$, Wet weight $(\mathrm{g})$ Dry weight $(\mathrm{g})$ Fat $\left(\mathrm{mgg}^{-1}\right)$ of fish sample studied is displayed in (Table 1). There was no significant difference between the three woods investigated $(\mathrm{P}>0.05)$ in benzo $\mathrm{b}$ fluoranthene and benzo a pyrene (Table 2) but significant differences $(\mathrm{P}<0.05)$ in $\mathrm{PAH}$ occurred between the 3 wood-smoked fish in acenaphthene, fluorine, phenathrene, anthracene, pyrene, dibenzo ah anthracene, benzo ghi pyrene, indeno $123 \mathrm{c}$ pyrene, fluoranthene with lowest value in PWS. Naphthalene

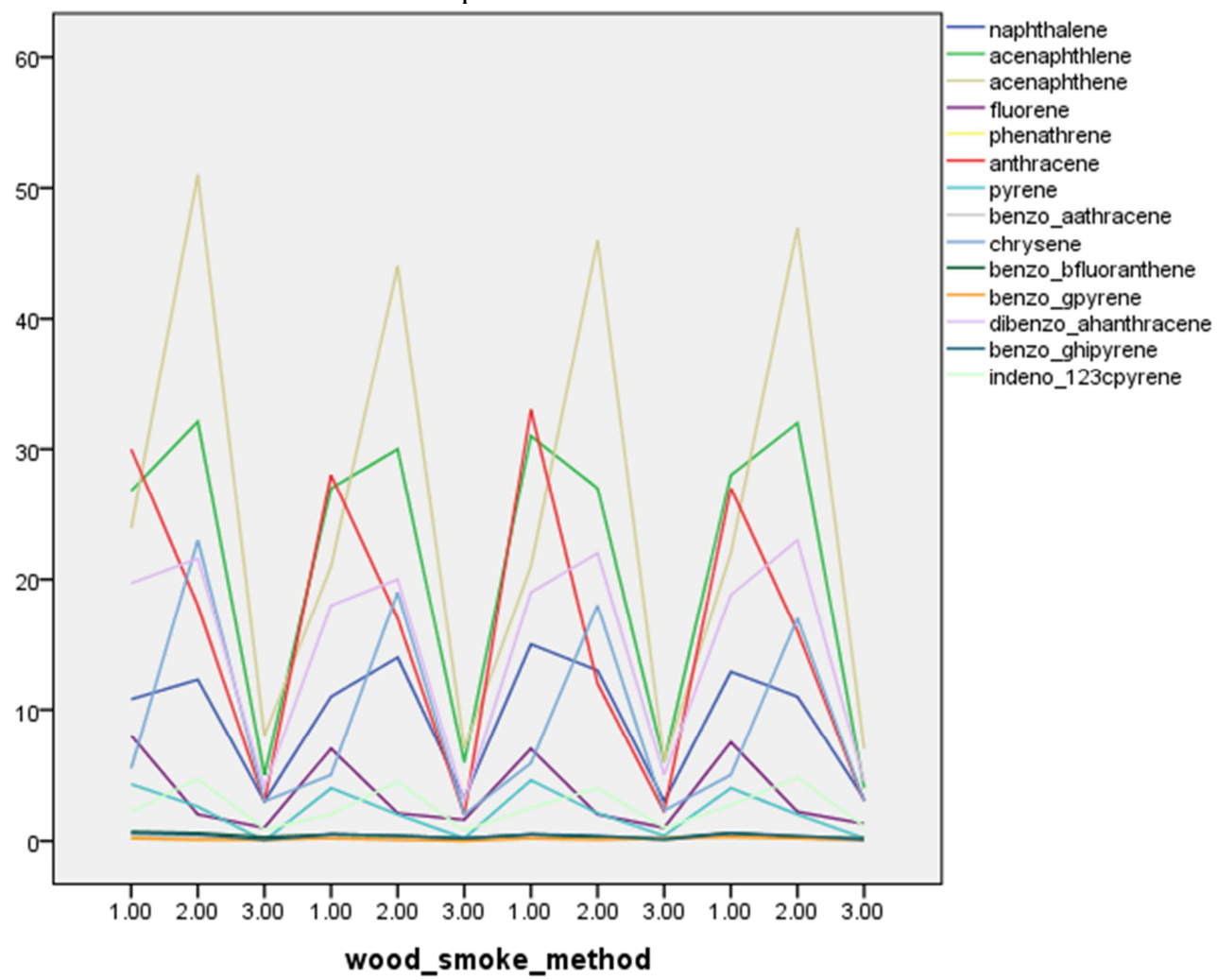

Figure 1. Sequencing of PAH for HWS, SWS and PWS smoked fish.

\section{Discussion}

The level of total PAHs in the smoked fish varies due to the different heat sources. This agrees with the findings of some researchers who studied the effects of cooking method and acenaphthylene had same value in HWS and SWS but were significantly lower in PWS. Conversely, benz_a athracene showed higher value in HWS compared to SWS and PWS but chrysene displayed higher value in SWS compared to PWS and HWS (Table 2).

Table 2. Mean PAH \pm SEM in PWS, HWS and SWS smoked fish.

\begin{tabular}{llll}
\hline PAH & PWS & HWS & SWS \\
\hline Naphthalene & $3.10 \pm 0.06^{\mathrm{b}}$ & $12.43 \pm 0.98^{\mathrm{a}}$ & $12.58 \pm 0.63^{\mathrm{a}}$ \\
Acenaphthylene & $5.25 \pm 0.48^{\mathrm{b}}$ & $28.20 \pm 0.97^{\mathrm{a}}$ & $30.28 \pm 1.19^{\mathrm{a}}$ \\
Acenaphthene & $7.00 \pm 0.41^{\mathrm{c}}$ & $21.97 \pm 0.68^{\mathrm{b}}$ & $47.00 \pm 1.47^{\mathrm{a}}$ \\
Fluorine & $1.23 \pm 0.14^{\mathrm{c}}$ & $7.37 \pm 0.24^{\mathrm{b}}$ & $2.08 \pm 0.05^{\mathrm{a}}$ \\
Phenathrene & $0.07 \pm 0.04^{\mathrm{c}}$ & $0.23 \pm 0.05^{\mathrm{b}}$ & $0.48 \pm 0.04^{\mathrm{a}}$ \\
Anthracene & $2.55 \pm 0.26^{\mathrm{c}}$ & $29.5 \pm 1.32^{\mathrm{b}}$ & $15.75 \pm 1.31^{\mathrm{a}}$ \\
Pyrene & $0.20 \pm 0.07^{\mathrm{c}}$ & $4.23 \pm 0.14^{\mathrm{b}}$ & $2.18 \pm 0.14^{\mathrm{a}}$ \\
benz_a athracene & $0.10 \pm 0.03^{\mathrm{b}}$ & $0.40 \pm 0.07^{\mathrm{b}}$ & $0.23 \pm 0.02^{\mathrm{a}}$ \\
Chrysene & $2.58 \pm 0.25^{\mathrm{b}}$ & $5.35 \pm 0.21^{\mathrm{b}}$ & $19.25 \pm 1.31^{\mathrm{a}}$ \\
benzo_b fluoranthene & $0.23 \pm 0.03^{\mathrm{b}}$ & $0.57 \pm 0.04^{\mathrm{b}}$ & $0.40 \pm 0.07^{\mathrm{a}}$ \\
benzo_a pyrene & $0.10 \pm 0.03^{\mathrm{a}}$ & $0.23 \pm 0.10^{\mathrm{a}}$ & $0.13 \pm 0.04^{\mathrm{a}}$ \\
dibenzo_ah anthracene & $4.13 \pm 0.42^{\mathrm{c}}$ & $18.88 \pm 0.34^{\mathrm{b}}$ & $21.65 \pm 0.62^{\mathrm{a}}$ \\
benzo_ghi pyrene & $0.13 \pm 0.02^{\mathrm{c}}$ & $0.55 \pm 0.02^{\mathrm{b}}$ & $0.43 \pm 0.02^{\mathrm{a}}$ \\
indeno_123c pyrene & $0.95 \pm 0.06^{\mathrm{c}}$ & $2.35 \pm 0.16^{\mathrm{b}}$ & $4.5 \pm 0.18^{\mathrm{a}}$ \\
Fluoranthene & $6.25 \pm 0.62^{\mathrm{c}}$ & $18.25 \pm 3.12^{\mathrm{b}}$ & $31.50 \pm 0.64^{\mathrm{a}}$ \\
\hline
\end{tabular}

Same letter super script are equal but different letter superscript are not equal at $\mathrm{P}<0.05$ 
including $1-\mathrm{OH}$ pyrene $(1-\mathrm{OH}-\mathrm{Pyr})$ and $3-\mathrm{OH}$ benzo a pyrene (3-OH-pyrene) [18]. Presence of 3, 4 - benzo pyrene found in smoked products, serves as an indicator of the possible presence of other polycyclic aromatic hydrocarbons used repeatedly as a quantitative index of chemical carcinogens in foods [15]. PAHs generation during grilling or barbecue through pyrolysis during charcoal broiling of meat products and either deposition and penetration of smoke components into foods and they found a link between that foods and PAHs levels. The hypothesis is that melted fat from the heated fish or meat drips onto the hot wood or coals and is pyrolyzed, giving rise to PAHs generation which are then deposited on the fish surface as the smoke rises $[12,6$, $21,7,8,10,18]$. Biological membranes are mostly composed of lipids (oils), majority of organic pollutants are lipophilic. It has been suggested that the larger the lipid content of the biological membrane, the higher is the rate of uptake of pollutants [3].

\section{Conclusion}

It can be concluded that the use of oil palm wood Elaeis guineensis is preferred in smoking of $C$. gariepinus compared to soft wood of Bamboo and hard wood of Mahogany. The three woods however did not display high value of benz_a anthracene since highest recorded in HWS fell below carcinogenic ranges.

\section{References}

[1] Agerstad MJ, Skog K. Review of genotoxicity of heat processed foods. Mutation Research/Fundamental and Molecular Mechanisms of Mutagenesis 2005, 574:156-172.

[2] Al-Jedah JH, Ali MZ, Robinson KK. The nutritional importance to local communities of fish caught off the coast of Quatar. Journal Food Science 1990, b:288-294.

[3] Anyakora C, Coker H. Assessment of poly-nuclear aromatic hydrocarbon content in four species of fish in the Niger Delta by gas chromatography/mass spectrometry. African Journal of Biotechnology 2007, 6:737-743.

[4] Anyakora C, Ogbeche A, Palmer P, Coker H, Ukpo G, Ogah C. GC/MS analysis of poly-nuclear aromatic hydrocarbons in sediment samples from the Niger Delta region. Chemosphere 2005, 60 (7): 990-997.

[5] Chelng SY, Ramesh RY, Krm JS, Kwon K, Kim MC, Min BD. Effects of grilling and toasting on the levels of polycyclic aromatic hydrocarbons in beef and pork. Food Chemical 2011, 129 (4):1420-1426.

[6] Chen BH, Lin YS. Formation of polycyclic aromatic hydrocarbons during processing of Duck meat. Journal Agriculture Food chemical 1997, 45 (4):1394-1403.

[7] Chen BH, Chen YC. Formation of polycyclic aromatic hydrocarbons in the smoke from Heated model lipids and food lipids. Journal Agriculture Food chemical 2001, 49 (11). 5235-5243.
[8] Chen BH, Lin YS. Formation of polycyclic aromatic hydrocarbons in smoke from heated model clipids and food lipids. Journal Agriculture Food Chemical 2001, 49:52385243.

[9] Clucas IJ. Fish Handling, Preservation and Processing in the Tropics Part 1 Report of the Tropical Development and Research Institute 1981, G 144, 8 - 141.

[10] Deudahl- Olesen L, Qhite S, Binderup ML. Polycyclic aromatic hydrocarbons (PAHs) in Danish smoked fish and meat products. Polycycyclic Aromatic Compound 2006, 26 (3):163-184.

[11] Farhadian A, Jinap S, Han Fah HN, Zaidual IS. Effects of meat preheating and wrapping on the levels of polycyclic aromatic hydrocarbons in charcoal grille meant. Food Chemicals 2011, 141-146.

[12] Garcia-Falcon MSG, Amig G, Lma Y, Villaizan MJ Lozano SL. Enrichment of benzo a pryrene in smoked food products and determination by high-performance liquid chromatography fluorescence. Journal of Chromatogram. 1996, 763:207-215.

[13] Gomez- Estaca J, Gomez-Guillen MC, Montero P, Sopelana P, Guillen MD. Oxidative stability, volatile components and polycyclic aromatic hydrocarbons of cold-smoked sardine (sardine pilchardus) and dolplin fish (corphaena hippurus). LWT - Food Science Technology 2011, 44:1517-1524.

[14] Guillen MD, Sopelana P. Occurrence of polycyclic aromatic hydrocarbons in smoked cheese Journal Diary Science 2004, 87:556-564.

[15] JECFA Joint FAP LWHO Experts committee on food additives. Sixty-fourth meeting Rome, 8-17 February 2005 Summary and conclusions. Rome: FAO/WHO. http//www.who.intli[1s/food/jecta/summaries/summary.report64-final.pdt.

[16] Ishizaki A, Saitoa K, Haniokab N, Narimatsub S, Kataokaa H. determination of polycyclic aromatic hydrocarbons in food samples by automated on-line in-tute solid-phase microexraction coupled with high-performance liquid chromatography-fluorescence detection. Journal of Chromatogram 2010, 1217:5555.5563.

[17] Muthumbi W, Boever P, Pieters JG, Siciliano S, Verstraete W. Polycyclic aromatic [hydrocarbons (PAHs) and estrogenic compounds in experimental fluid and gas steams. Journal Environmental Quality 2003., 32:417-422.

[18] Rey - Salgueiro L, Garcia - Falcon MS, Soto-Gomalez B, Simal-gandara J. Occurrence of polycyclic aromatic hydrocarbons and their hydroxylated metabolites in infant foods. Food Chemistry 2009, 115:814-819.

[19] Simko P. Determination of polycyclic aromatic hydrocarbons in smoked meat products and smoke flavoring food additives. Analytical Technology, the Biomedical and life sciences Journal chromatogram 2002, 770:3-18.

[20] Stolyhwo A, Sikorski Z. Polycyclic aromatic hydrocarbons smoked fish - a critical review food chem. 2005, 91: 303-311.

[21] Wu J, Wong MK, Lec HK. Determination of polycyclic aromatic hydrocarbons in rougan, a traditional Chinese barbecued food, by capillary gas chromatography. Environmental Monitoring Assessment 1997, 44:577-585. 